\title{
Characterization of Tree Crops Biomass from Marginal Lands as Feedstock for Solid Biofuels
}

\section{Vasiliki Kamperidou ( $\square$ vkamperi@for.auth.gr)}

Aristotle University Of Thessaloniki Department of Forestry and Natural Environment: Aristoteleio Panepistemio Thessalonikes Tmema Dasologias kai Physikou Periballontos https://orcid.org/0000-0003-3276-9394

Paschalina TERZOPOULOU

Aristotle University Of Thessaloniki Department of Forestry and Natural Environment: Aristoteleio Panepistemio Thessalonikes Tmema Dasologias kai Physikou Periballontos

loannis BARBOUTIS

Aristotle University Of Thessaloniki Department of Forestry and Natural Environment: Aristoteleio Panepistemio Thessalonikes Tmema Dasologias kai Physikou Periballontos

\section{Original Research}

Keywords: ash, biomass, combustion, heating value, marginal land, pellets

Posted Date: February 4th, 2021

DOI: https://doi.org/10.21203/rs.3.rs-167490/v1

License: (c) (i) This work is licensed under a Creative Commons Attribution 4.0 International License. Read Full License 


\section{Abstract}

Even though the biomass production on marginal lands intended to be used as biofuel production feedstock has been proposed as an alternative viable option for meeting biofuel requirements and address the conflict between food and fuels, there are still concerns whether the species grown on marginal lands can have a high quality performance as solid biofuels feedstock. In this study, material of stem wood, branches and bark of three native forest species of Mediterranean region, turkish pine, black pine and black locust was harvested from marginal lands of North Greece, and thoroughly characterized on the basis of physical properties, combustion characteristics, chemical composition, and ash elemental analysis. The potential of these fast-growing drought-tolerant species to contribute as sustainable feedstock for qualitative solid biofuels production is high, with black pine to present the highest potential. The materials presented low moisture and ash contents, especially stems and branches, and high calorific values, comparable to species grown on conventional lands, attributed to high lignin contents. The materials ashes consist mainly of $\mathrm{Ca}$, $\mathrm{K}$, S, P major elements and their toxic elements contents are negligible, increasing the ashes potential to be utilized in fertilizing.

\section{Introduction}

As the number of population keeps rising, expecting to reach 9.7 billion till 2050 [1], the demands for cultivation land for food and feed production increase. Parallel, the cultivation of non-food biomass crops for biofuels and biomaterials raw materials contributes as well, to the global requirement for agricultural land use [1]. Unfortunately, conventional biofuels produced directly from food crops intensively contribute to land use changes and forest ecosystems degradation [2,3]. Therefore, both the rational use of traditional agricultural lands and the utilization of marginal lands have recently come to the forefront of the global attention [4].

Marginal lands have been considered a viable alternative of land resources contributing to food, feed, and biofuels production [5, 6]. Mainly due to low quality underground water, undesired topology or unfavorable soil or climatic conditions, they present low productivity for conventional crops and low profitability potential [3]. In the term of marginal lands, a wide variety of lands is included, such as waste, fallow, abandoned, set-aside, or degraded lands [7] that totally account approximately $36 \%$ of global agricultural land [8]. The cultivation of marginal lands is imperative, because of the shortage of conventional agricultural lands and crucial, especially for developing countries [9], where the need of food is even higher. Parallel, the necessary energy crop supplies could be almost totally covered by the marginal lands low quality production [10]. The production of biomass and biofuel from marginal and degraded lands is characterized by several advantages, such as the addressing of the energetic needs, decrease of emissions, ecosystem rehabilitation, wildlife habitats creation, soil carbon sequestration and smoothing the conflict between food and biofuels production $[11,12]$. However, they are of lower productivity and more susceptible to land degradation compared to the conventional agricultural lands [13].

Some studies have been carried out examining annual crops, which typically require intensive land management, higher effort and energy inputs and may therefore not be a viable biofuel option to be established on marginal lands [5]. Evidence from thorough experimental studies indicates that higher yields of energy and environmental benefits can be achieved using perennial energy crops, since they provide higher yields, water use efficiencies, require lower energy inputs, management practices and nutrients, than annual crops [2, 14-17].

Perennial grasses present a positive environmental impact, since they affect hydrological processes, water quality, biodiversity, ecosystem processes and services, such as soil carbon sequestration, degraded soils restoration and soil quality improvement [18-20], and as droughtresistant crops, they grow on marginal land, staying out of the competition for conventional agricultural lands [1].

Compared to perennial energy plants, the advantages of energy-trees wood biomass are even more and include lower ash contents and higher calorific values [21]. The numerous benefits that we get from the presence of forest ecosystem, such as land restoration, soil improvement, biodiversity, non-wood forest products, wood and wood-based products, biomaterials, chemical wood products, firewood and biofuels [3, 22], could be obtained through the establishment of energy-tree species cultivation on marginal lands. Nowadays, approximately $40 \%$ of wood production, which corresponds to 3.5 billion $\mathrm{m}^{3}$ of annually harvested wood, is being used as fuel [23]. Energy production based on wood biomass coming from marginal lands could meet the household energy demands, thus reducing the intense pressure that forests receive through logging [24].

In warm and dry climates, such as that of Mediterranean region, agricultural lands are experiencing more intensely the impact of global warming, with lower precipitation level and higher temperatures. Fast-growing tree crops with tenacious root system could be efficiently adapted to such lownutrient, dry and erodible soils, retaining higher capacities of atmospheric $\mathrm{CO}_{2}$ into soil and biomass. Therefore, marginal lands could be converted into bioenergy forest lands, where biomass produced can be turned into energy, conferring the additional financial and environmental benefits.

There are several factors which may influence positively the biomass productivity on marginal lands, such as irrigation, coppicing and crop rotation duration, fertilizer application, keeping a balance between cost and gain from the respective yield increase [25]. According to the literature review, the potential of the forest species of poplar, eucalyptus and short-rotation coppice willow cultivation has been investigated, as fast-growing species, in biomass production for their contribution in bioenergy providing promising results $[3,9,26,27]$. These efforts should be characterized by planting the right species, at the right place, for the right rotation period [25]. Except for the level of yield, other crucial issue is the level of crops moisture content at the time of harvest, since it determines the biomass technical drying expenses. Optimally, the biomass would be harvested at such a low 
moisture content that technical drying would be avoided [1]. At the time of combustion, the moisture content of solid biofuels should be very low to avoid negative impact on their calorific value, the loss of heat, to keep the amount of combustion gases low, to maintain an optimum biomass combustion rate and optimum inflammation [28].

Turkish pine is a fast-growing, drought-tolerant conifer species, native to Mediterranean region, well adapted to dry summer conditions and commonly found in zones of low altitude. It has been widely planted for soil stabilization, afforestation of slopes and protection from the wind, the previous decades. It is commonly encountered together with cypress, juniper, oak or other drought-tolerant species in mixed forests. Black pine is a moderately variable pine species, encountered across southern Mediterranean Europe at elevations ranging from sea level to 2,000 metres, most commonly from $250-1,600 \mathrm{~m}$. It is a highly fast-growing, light-demanding species, intolerant of shade, but resistant to cold, ice, wind, drought and pests [29]. It is used for landscaping, afforestation of steep slopes and stony soils, aiming at harvesting of wood and other forest products [30]. Black locust is a tough, fast-growing, salt-tolerant and shade-intolerant species and therefore, is typical of young forestlands and disturbed areas of dry soil. Black locust root system bears nitrogen-fixing bacteria, making this species grow easily on poor soils and in disturbed areas. It is considered an invasive species, due to its spread by underground shoots or suckers, forming clusters that often eliminate native species. It has been used as a plant for erosion control [31].

This study aims at triggering the utilization of currently undesirable marginal lands allocated to the Mediterranean region for biofuel feedstock production and the promotion of plantations of the abovementioned significant bioenergy tree species of short-rotation, on mountainous degraded lands. Specifically, turkish pine, black pine and black locust biomass, is harvested from marginal lands of North Greece, isolating and examining different tree parts (stem, branches and bark) of them, which are thoroughly characterized on the basis of physical properties, combustion characteristics, chemical composition, and ash elemental analysis. Aim is to investigate and demonstrate the quality performance of these fastgrowing indigenous forest species materials and the potential of their contribution as feedstock of qualitative solid biofuels.

\section{Materials And Methods}

For the purpose of this work, material of stem wood, branch wood and bark of three different fast-growing, drought-tolerant and indigenous to Mediterranean region species, turkish pine (Pinus brutia Ten.), black pine (Pinus nigra L.) and black locust (Robinia pseudoacacia L.), was harvested from 3 different marginal sites of Rhodope mountains region in North Greece. According to sampling method described in EN 14778:2011 standard, two trees per species were harvested as raw material to be thoroughly analyzed, in order to assess their quality performance as solid biofuels sustainable feedstock. The turkish pine trees were at the age of 24 and 27 years with barked diameters of $140-170$ mm, the black pine trees were at the age of 22 and 26 years with barked diameters of $110-150 \mathrm{~mm}$, while the two trees of black locust species were 13 and 15 years old with barked diameters of $80-105 \mathrm{~mm}$. They were harvested at late autumn, in order to ensure lower moisture contents, which shortly after cutting ranged between $55-70 \%$.

Concerning these 3 marginal land sites, which are currently used mainly for forestry and partly for low-intensity pasture (meadow) systems, the productivity is clearly limited for traditional agriculture, because of the shallow soil depth on hard rock, situated partly on steep slopes. The soil substrates are in part highly stony, both at the surface and in deeper profile levels and reveal naturally poor soil conditions, as a result of previous erosion and degradation, caused by the natural constraints and the anthropogenic disturbance, occurred during a more intensive land use (deforestation, pasture) of previous years. The altitude is between 100 and $590 \mathrm{~m}$ a.s.l. and the relief is mountainous.

In the frame of Mediterranean climate, droughts are frequent phenomena in Greece, especially during the summer season and the study area (North Greece) is characterized by semi-arid climatic conditions. The prevailing conditions and the species requirements were the main factors that led to the choice of the specific native and drought-tolerant species to be included in this experimental work.

All the materials were cut in smaller dimensions (discs of $20 \mathrm{~mm}$ thickness) and placed in the laboratory at $(20 \pm 2){ }^{\circ} \mathrm{C}$ and $(60 \pm 5) \%$ relative humidity for about one year to reach a nominal equilibrium moisture content (EMC) (\%) till constant weight. The EMC of the materials was measured on small clear wood specimens using the standard ISO 13061-1:2014, based on their weight loss after drying process. The mean density of turkish pine, black pine and black locust stem wood was measured on clear prismatic specimens, based on the methodology of ISO 130612:2014 standard, and was found to be $0.512,0.442$ and $0.765 \mathrm{~g} / \mathrm{cm}^{3}$, respectively. From each stem, material from different heights and different growth rings was included to be analyzed, to ensure the representativeness of the samples. Pieces of bark were taken at the height of $1.30 \mathrm{~m}$, as well as different heights on 2 opposite sites of the stem diameter.

The discs of the species were cut into smaller particles and then, into wood powder for the preparation of properties examination samples. All the lignocellulosic materials were crushed by means of a portable chipper into pieces, and placed in a rotating-blade "Wiley" mill (Thomas Scientific, Swedesboro, USA) with a $0.7 \mathrm{~mm}$ sieve, where they were ground and converted into powder of dimensions $>40 \mathrm{mesh}(420 \mu \mathrm{m})$.

The net calorific values of the different biomass materials were determined according to the methodology described in EN ISO 18125 , using an isoperibol bomb calorimeter (Parr 1261, Parr Instrument Company, Moline, IL, USA) (Fig. 1a). The calibration and validation of the calorimeter before the measurements were implemented using benzoic acid pellets. The net calorific values measurements were conducted in 5 replicates for each material. Sample pellets in the shape of pills of $1.0 \pm 0.1 \mathrm{~g}$ mass, of $13 \mathrm{~mm}$ in diameter were prepared (Fig. $1 \mathrm{~b})$ using a hydraulic pellet press

Page $3 / 11$ 
(custom made, Thessaloniki, Greece) applying force of $6000 \mathrm{~kg}$ for $1 \mathrm{~min}$. The sample pellets, weighed to the nearest of $0.01 \mathrm{~g}$ in a crucible, were loaded into a Paar 1108 oxygen combustion bomb, in contact with $100 \mathrm{~mm}$ of pre-weighed platinum ignition wire. The bomb was subsequently charged with oxygen (purity of $99.7 \%$ ) at 30 bar \pm 2 bar and submerged in a stainless steel bucket containing $2000.0 \mathrm{~mL}$ of distilled water, conditioned at $33 \pm 0.5^{\circ} \mathrm{C}$. The calorimeter jacket was maintained at a constant temperature by circulating the water at $35^{\circ} \mathrm{C}$ to preserve a slightly higher temperature than the final temperature of the calorimeter, to assure that evaporation losses were minimized.

For the chemical analyses implementation, determination of solubility in ethanol-toluene mixture was performed on the basis of ASTM D1107-96. The determination of the total amount of extracts, soluble in ethanol-toluene mixture was implemented according to ASTM D1105-96. Holocellulose content was quantified by removing lignin from the dry, free of extracts wood powder. $10 \mathrm{~mL}$ of the chlorine solution of $\mathrm{NaClO}_{2}(25 \%)$ was applied to $1 \mathrm{~g}$ wood powder in a water bath set at $70^{\circ} \mathrm{C}$ for 5 hours, making lignin oxidized and cleaved into soluble derivatives thereof which are removed by extraction, whereby the holocellulose remains intact as a residue. At the end of this process, the sample was rinsed with cold water until $\mathrm{Cl}_{2}$ was completely removed and placed in a drying chamber. The dry sample was placed in a desiccator and then weighed. The holocellulose is quantified as a percentage value of the initial mass of the extracts-free wood powder sample. For each holocellulose sample obtained after rinses, the process was repeated till constant weight. Three replicates were tested for each material. The quantification of lignin, according to ASTM D1106-96, was based on the hydrolytic cleavage of polysaccharides with inorganic acid $\left(\mathrm{H}_{2} \mathrm{SO}_{4}\right.$ of $\left.72 \%\right)$, which results in the depolymerization and removal of their soluble derivatives, while the lignin remains insoluble as residue and is determined as a percentage of the absolute dry weight of the sample. Three replicates were tested for each material.

For the determination of ash content, the methodology of ISO 18122 was followed. Wood powder samples of $1 \mathrm{~g}-1.1 \mathrm{~g}$ were weighed to the nearest $0.1 \mathrm{mg}$ in the dry, clean and pre-weighed crucibles and then, transferred in a cold muffle furnace (Heraeus MR 170). The samples were heated to $250^{\circ} \mathrm{C}$ within $50 \mathrm{~min}$ and the temperature was kept constant for $60 \mathrm{~min}$. Next, the temperature was raised to $550^{\circ} \mathrm{C}$ within 60 min and was maintained at that level for $3 \mathrm{~h}$. Finally, the crucibles were transferred to an empty desiccator without lid for 5 min followed by 15 min with closed lid and then weighed. To ensure any unburned carbon was removed, the samples were reloaded to be heated for 30 min more, conditioned and reweight, repeating this process till constant weight. The ash content of powder material on dry basis was calculated according to Eq. (1):

$A d=\left[\frac{\left(m_{3}-m_{1}\right)}{\left(m_{2}-m_{1}\right)}\right] * 100$

where, $A d$ is the ash content (\%), $m_{1}$ is the mass of empty crucible (g), $m_{2}$ is the mass of the crucible plus the dried powder sample (g) and $m_{3}$ is the mass of crucible plus ash $(\mathrm{g}) .3$ replicates were examined per type of material.

The chemical composition of ash from biomass is an important issue providing crucial information for evaluation of the performance of elements during combustion of biomass in furnaces [32], associated to phenomena of corrosion and ash deposition in combustors, as well as the additional utilization of ash materials. To measure the produced ashes elements content, pelletized discs of 12 mm diameter were prepared using the abovementioned hydraulic press. For the elemental analysis of the ashes, the X-ray Fluorescence spectroscopy (XRF) technique was applied, as a fast and convenient method, using the HDMaxine multi-element analyzer for the determination of trace elements based on the High Definition X-ray Fluorescence (HDXRF). For each ash material category, 2 replicates were examined. Because of difficulties to produce sufficient quantities of bark ashes of the 3 studied species, only the ashes of stem and branch material of the selected species were examined.

The statistical package SPSS Statistics PASW 18 was used to determine the statistically significant differences among the mean values of properties of the different biomass materials. Through a multiple linear regression analysis, the potential, the significance $(p<0.05)$ and the degree (\%) of influence of the independent variables (forest species, tree part, chemical components contents), on the dependent variable (heating value) were investigated, in order to assess correlations potential among properties.

\section{Results And Discussion}

Combustion characteristics of the different forest species and the different parts of the trees studied are presented in the following. The materials were generally of low moisture content at the time of harvesting (55-70\%), compared to other species, annual or perennial plants, or other types of biomass, which is beneficial to their management and cost-effectiveness as feedstock, since it lowers the cost of drying and pre-treatment.

The moisture content of materials at the time of combustion is an important parameter for the combustion process. The values of equilibrium moisture contents (EMC) of the examined materials, achieved after a conditioning process, are presented in Fig. 2. Only the stem wood and branch wood of turkish pine presented significantly lower values of EMC, in relation to the other two forest species parts. However, all the examined materials presented very low EMC, which indicates that after a natural or, even faster, a technical drying process, all the studied materials could be used as feedstock of solid biofuels production, according to the requirements of the respective standards of biofuels, for example that of pellets that sets the moisture content threshold of $10 \%(<10 \%)$ for residential use quality classes, ENplus A1, A2 and B (ISO 18134). 
According to the results of chemical analyses (Fig. 3), the highest contents of extractives were found in bark material of the three species (9.45$18.93 \%)$, a little lower contents in branches (6.54-11.43\%) and the lowest extractives contents were recorded in the material of stems (2.74$7.44 \%)$. Concerning the stems and branches, black locust presented the highest extractives content, compared to the other species, marking statistically significant differences from the other two species. The two pines, as it was expected for softwoods, presented higher contents of lignin compared to the hardwood of black locust, with black pine to record the highest lignin contents among the examined species, which is a tendency recorded both in stem and branch materials. The black locust recorded similar values of holocellulose to those of the two pine species, though concerning the branches, the mean holocellulose value of black locust was found significantly higher than the respective values of pines. The highest values of holocellulose content were recorded in bark materials and the lowest ones in branches parts. In the case of bark, high lignin contents were recorded, similar to lignin contents of stems, with black pine and black locust to reveal similar values of lignin content one another.

The ash contents of all the three forest species were found quite low, ranging from 0.38 to $0.72 \%$ for the stem wood materials and 0.32 to $0.87 \%$ for the branch wood materials, indicating that stem and branches can be utilized as feedstock for solid biofuels of premium quality (wood chips, pellets, briquettes etc.). Specifically, the pellets standard for the best quality class (ENplus A1) requires the ash content to be lower than $0.7 \%$ and for the second class ENplus A2 to be less than $1.2 \%$, while the third quality class of residential use (ENplus B) sets the threshold of $<2 \%$. Nevertheless, the ash contents of bark material of all the three species, were found significantly higher, ranging between $3.42-4.67 \%$, indicating that these materials could not be used by themselves as feedstock of solid biofuels for residential use, but they could participate in smaller parts with wood of stem and branches, in order to keep the total ash content in low levels. Additionally, they could participate at higher percentages as raw materials in pellets production, intended to be used in industrial energy applications, where the threshold of ash content is < $3 \%$ (ISO $18122: 2015$ ).

The net calorific value of black pine was found to be significantly, from a statistical point of view, higher than the other two species, which tendency refers both to stem and branch material, while the black locust presented the lowest value, respectively (Fig. 4), though without marking statistical difference from the respective values of turkish pine. The highest calorific value of black pine can be attributed to the higher lignin and extractives contents. Lignin is rich in carbon and hydrogen, and therefore, has a high calorific value and is a key component in the process of biomass conversion into energy, while ash content adversely affects the calorific value [21]. The net calorific values of branches were found to be a little higher than those of stem material, presenting the same tendencies among the three species. The bark material recorded lower calorific values compared to respective values of stem or branch materials of the same forest species, except for the case of black locust, whose bark recorded higher calorific value than stem or branch, though the recorded differences were not statistically significant. The reduced heating values of bark materials could be explained by the higher ash contents they are characterized by, which present the tendency to turn the heating value down [21, 33]. Generally, all the materials were found to fulfill the requirements of the respective solid biofuels standard ISO 18125:2017, concerning the net calorific value of the raw materials, that sets the threshold of $\geq 3955.288 \mathrm{kcal} / \mathrm{kg}$ for the three quality classes of residential use (ENplus A1, A2 and B). Therefore, in terms of calorific value, all the materials could be used as feedstock of wood pellets, both for residential or industrial energy applications.

Orwa et al. [34] in their study found that the calorific value of absolutely dry black locust wood was about $4.633 \mathrm{kcal} / \mathrm{kg}$, which is only slightly higher than the value recorded in this study. Likewise, Cosola [35] found that black pine marked net calorific value of $4929 \mathrm{kcal} / \mathrm{kg}$ for the branches, $4781 \mathrm{kcal} / \mathrm{kg}$ for the bark and $4815 \mathrm{kcal} / \mathrm{kg}$ for the stem wood material. Even though their study revealed slightly higher calorific values, than those recorded in the present study, it revealed also the same tendency of values, with branches to present the highest calorific values, followed by the stem material and bark to present the lowest calorific values. Generally, the values found in the literature were similar or slightly higher, than those measured and recorded in this study, which differences are mainly attributed to the fact that the these species were grown on different substrates, and not on such degraded and poor ones of marginal sites, as those that the examined species came from.

According to the statistical analysis of the results, the Levene's test revealed that the null hypothesis that the error variance of the dependent variable (heating value) is equal across the groups, was accepted (6th requirement of a successful ANOVA), recording a significance level $>0.05$ (Sig. 0.753). The factor "Species" was found to be statistically significant and the most crucial one, affecting the variability of heating value by $77.2 \%$. The factor "Tree part" was not statistically significant and affected the heating value variability only by $15.9 \%$, while the interaction of both factors was found to significantly affect heating value variability by $47.5 \%$.

The results of the multiple linear regression analysis of the examined properties showed that there is a statistically significant (sig. 0.004 ) correlation between the heating value, which is considered as the dependent variable, and the contents of chemical components of the materials examined (Fig. 5). Specifically, the $49.5 \%$ of the heating value variability is attributed to the interaction among all the examined chemical components contents (lignin, holocellulose, extractives, ash). The component, that most intensely, and significantly from a statistical point of view (0.000091), influences the heating value, by $66 \%$, is lignin, presenting a positive impact. This indicates that as the lignin content increases, the heating value increases as well. A strong correlation (0.000004) was detected between ash content and extractives, which indicates that the variability of one is influenced positively, by $74.8 \%$, by the other. As it was expected, lignin and holocellulose contents are significantly (0.000399) correlated one another with a negative impact (60.7\%). 
Table 1

Mean content (\%) values of individual mineral components in biomass ashes resulted from the combustion of the examined materials, turkish pine, black pine and black locust

\begin{tabular}{|c|c|c|c|c|c|c|}
\hline \multirow[t]{2}{*}{ Element } & \multicolumn{2}{|c|}{ Turkish pine } & \multicolumn{2}{|c|}{ Black pine } & \multicolumn{2}{|c|}{ Black locust } \\
\hline & Stem & Branch & Stem & Branch & Stem & Branch \\
\hline $\mathrm{CaO}$ & 59.05 & 57.92 & 45.33 & 42.47 & 49.46 & 43.05 \\
\hline $\mathrm{K}_{2} \mathrm{O}$ & 26.40 & 24.92 & 28.98 & 29.70 & 39.75 & 42.03 \\
\hline $\mathrm{SO}_{3}$ & 5.23 & 5.41 & 4.30 & 4.83 & 5.41 & 4.67 \\
\hline $\mathrm{P}_{2} \mathrm{O}_{5}$ & 3.50 & 3.65 & 6.10 & 6.83 & 2.66 & 6.76 \\
\hline $\mathrm{MgO}$ & 3.50 & 4.39 & 6.30 & 6.71 & 1.44 & 1.99 \\
\hline MnO & 0.94 & 1.30 & 2.71 & 2.71 & - & - \\
\hline $\mathrm{Fe}_{2} \mathrm{O}_{3}$ & 0.68 & 1.52 & 1.34 & 1.50 & 0.30 & 0.32 \\
\hline Zno & 0.17 & 0.27 & 1.05 & 1.26 & - & 0.08 \\
\hline SrO & 0.05 & 0.04 & 0.05 & 0.28 & 0.08 & 0.10 \\
\hline CuO & 0.07 & - & 1.04 & 1.71 & - & 0.10 \\
\hline $\mathrm{SiO}_{2}$ & - & - & 1.12 & 1.22 & - & - \\
\hline $\mathrm{NiO}$ & - & - & 0.48 & 0.28 & 0.12 & 0.30 \\
\hline $\mathrm{PbO}$ & - & - & 0.26 & 0.18 & - & - \\
\hline $\mathrm{Rb}_{2} \mathrm{O}$ & - & - & - & - & 0.02 & 0.02 \\
\hline Total & 99.60 & 99.41 & 99.04 & 99.66 & 99.25 & 99.42 \\
\hline
\end{tabular}

The chemical composition analysis of ashes (Table 1) of all the materials, revealed that the major elements Ca, K, S and P prevailed in the composition, which indicates the high potential of utilization of these materials in nutrient recycling through fertilizing. The turkish pine presented the highest contents of $\mathrm{Ca}$, black locust the highest contents of $\mathrm{K}$ and black pine the highest contents of P. Only small differences in the composition were detected between stem and branches of the same species, while among the different species, the differences between the mean values of contents were statistically significant. Despite the longer rotation period of tree species and the longer period necessary for the wood biosynthesis, compared to other species, annual or perennial ones, which naturally is expected to result in higher contents of metal elements, the contents of toxic elements of the materials ashes examined in this study, were found very low, such as $\mathrm{Pb}$ and $\mathrm{Ni}$, which suggests a high potential of utilization in several applications, especially for turkish pine and black locust species. In addition, ashes of these biomass materials were found to be complemented with minor elements, such as $\mathrm{Zn}, \mathrm{Cu}$ and $\mathrm{Mn}$, which further supports their utilization scenarios in traditional agricultural, as well as marginal lands enrichment, as fertilizer. The recycling of ashes produced by the biomass combustion through their rejoin into soil is one of the most beneficial and sustainable ways of disposal, which ensures a balance in the nutrients and minerals and favors the quality of soil, especially in the case of marginal lands [32], contributing parallel to the land productivity maintenance. Additionally, the fact that the ashes obtained from the combustion of the examined biomass materials were found to contain negligible contents of toxic heavy metal elements, suggests favorable combustion process conditions in furnaces, proper operation and longer preservation of the combustion equipment. According to the requirements of standard ISO 16968 of wood pellets production, concerning the thresholds of $\mathrm{As}, \mathrm{Cd}, \mathrm{Cr}, \mathrm{Cu}, \mathrm{Pb}, \mathrm{Hg}, \mathrm{Ni}$, and $\mathrm{Zn}$ contents of the raw materials, the biomass materials examined in this study fulfill the criteria of their utilization as solid biofuels (pellets) feedstock.

Taking all the results of this study into consideration, the biomass obtained from the examined fast-growing, cold- and drought-tolerant forest species revealed good quality performance. Specifically, turkish pine, black pine and black locust make an excellent choice for energy production due to higher energy content and lower ash and moisture contents, than other woody biomass types and parallel of medium to high density, which is significant for the energetic density of the material and the space needed to store the feedstock. The calorific values of the materials examined in this study were found to be similar or only slightly lower, compared to the respective values found in literature, even though they refer mainly to conventional high-productivity lands, agricultural or forest ones. The chemical composition of the studied materials was found to be rich in lignin and extractives, which are two components of low oxidation degree and considerably high energy content and therefore, are mainly responsible for the higher calorific value of biomass [21,33]. Nevertheless, in this study the heating value was found to be correlated only to lignin content, and not to extractives content as it was expected especially for conifers with resinous extracts. The stems and branches could be used without any restriction in pellets production, of both residential and industrial energy applications, according to the standards requirements of ash contents, while the bark due to higher ash contents could only participate as a part of the raw material of the solid biofuels, especially of those intended for 
residential use, or participating in larger percentages in feedstock of pellets for industrial use. Generally, the examined species stems and branches presented very low ash contents (<0.87), compared to other species used for energy production purposes, which qualifies them (especially the stems) as pellets of premium quality, according to ENplus certification system and the requirements of the respective standards (ISO 18122:2015).

Of course, the examined materials could be managed for bioenergy purposes through several different energy conversion methods, including fermentation, pyrolysis, gasification, liquefaction and combustion. Compared to other types of biomass, conversion of the studied species biomass seems to be less complicated, since they are $99 \%$ combustible, they have very low content of toxic elements of ashes, and the feedstock management is simpler, since it is not necessary to apply any other pre-treatment process, except for the drying and reduction of materials dimensions. The factor of moisture content of the raw materials is crucial for their utilization as solid biofuels feedstock, therefore to ensure the minimum moisture content of the materials, the optimum harvesting time is late autumn to early spring [36]. Due to the different materials similarity in quality performance, the examined three species (especially stems and branches) could be mixed one another and used, as part of an integrated feedstock supply.

The sustainable cultivation of marginal lands using native, well adapted tree energy crops might be an attractive option for regional value chains and stakeholders networks and provide crucial environmental impacts, such as soil protection, land restoration and wildlife preservation etc. Such practices might also contribute to the objective to approach the national and European renewable energy goals for 2050 , and address the challenge to normalize the increasing land use conflict between the food/feed, and biomass production. The development of appropriate policy frameworks of financial support and regulations is necessary, while strengthening of the research efforts towards assessment of the potential of marginal lands to contribute in bioenergy production is highly recommended.

\section{Conclusions}

The high potential of the examined forest species to contribute as feedstock for qualitative solid biofuels production is illustrated, with black pine to present the highest potential. The materials presented relatively low moisture at harvest time, sufficiently low EMC contents, very low ash contents, especially the stems and branches, and high net calorific values, comparable to the respective species grown on conventional agricultural lands. The calorific values were strongly correlated to lignin, and not to the extractives as expected. Ca, $\mathrm{K}, \mathrm{S}$ and $\mathrm{P}$ prevailed in the materials inorganic part examined, with the presence of significant minor elements, while the toxic elements contents were found to be negligible, increasing ashes potential to be utilized in fertilizing applications.

\section{Declarations}

Funding: No funding was received to assist with the preparation of this manuscript.

Conflicts of interest: The authors have no relevant financial or non-financial interests to disclose. There is not any conflict of interests.

Availability of data and material: Not available or published yet.

Authors' contribution: Kamperidou Vasiliki: Conceptualization, Methodology, Investigation, Writing - Original Draft, Supervision. Terzopoulou Paschalina: Investigation, Visualization, Writing - Review \& Editing. Barboutis loannis: Methodology, Writing - Review \& Editing.

Compliance with Ethical Standards: The authors fully respect and accept the rules of ethics. The research does not include Human Participants and/or Animals.

Consent to participate: All authors agree with the content of the manuscript, approve the version to be published, to participate in this publication, all gave explicit consent to submit, obtained consent from AUTh University where the work has been carried out and agree to be accountable for all aspects of the work in ensuring that questions related to the accuracy or integrity of any part of the work are appropriately investigated and resolved.

Consent for publication: All authors agree our manuscript to be published in this journal.

\section{References}

1. Schmidt T, Fernando AL, Monti A, Rettenmaier N (2015) Life cycle assessment of bioenergy and bio-based products from perennial grasses cultivated on marginal land in the Mediterranean region. BioEnergy Res. 8, 1548-1561. https://doi.org/10.1007/s12155-015-9691-1.

2. Fargione JE, Plevin RJ, Hill JD (2010) The ecological impact of biofuels. Annu. Rev. Ecol. Evol. Syst. 41, $351-377$. https://doi.org/10.1146/annurev-ecolsys-102209-144720

3. Mehmood M, Ibrahim M, Rashid U, Nawaz M, Ali S, Hussain A, Gull M (2016) Biomass production for bioenergy using marginal lands. Sustainable Production and Consumption, http://dx.doi.org/10.1016/j.spc.2016.08.0032352-5509/ 
4. Popp J, Lakner Z, Harangi-Rákos M, Fári M (2014) The effect of bioenergy expansion: Food, energy and environment, Renew. Sust. Energ. Rev., 32, 559-578, https://doi.org/10.1016/j.rser.2014.01.056, 2014.

5. Gelfand I, Sahajpal R, Zhang X, Izaurralde RC, Gross KL, Robertson GP (2013) Sustainable bioenergy production from marginal lands in the US Midwest. Nature 493, 514-517. https://doi.org/10.1038/nature11811

6. Skevas T, Swinton SM, Hayden NJ (2014) What type of landowner would supply marginal land for energy crops? Biomass Bioenergy 67, 252259. https://doi.org/10.1016/j.biombioe.2014.05.011.

7. Dauber J, Brown C, Fernando AL, Finnan J, Krasuska E, Ponitka J, Styles D, Thrän D, Van Groeningen KJ, Weih M, Zah R (2012) Bioenergy from "surplus" land: environmental and socio-economic implications, BioRisk, 7, 5-50, https://doi.org/10.3897/biorisk.7.3036, 2012.

8. Wood S, Sebastian K, Scherr SJ (2000). Pilot Analysis of Global Ecosystems: agroecosystems. International Food Policy Research Institute and World Resources Institute, Washington, DC. ISBN: 1-56973-457-7. http://www.wri.org/wr2000 and http://www.ifpri.org

9. FAO, FAOSTATS (2008) Available at: 〈fao.org/metadata〉.

10. Aylott MJ, Casella E, Tubby I, Street N, Smith P, Taylor G (2008) Yield and spatial supply of bioenergy poplar and willow short-rotation coppice in the UK. New Phytol. 178, 358-370.

11. Edrisi SA, Abhilash P (2016) Exploring marginal and degraded lands for biomass and bioenergy production: An Indian scenario. Renew. Sustainable Energy Rev. 54, 1537-1551. https://doi.org/10.1016/j.rser.2015.10.050

12. Werling BP, et al. (2014) Perennial grasslands enhance biodiversity and multiple ecosystem services in bioenergy landscapes. Proc. Natl. Acad. Sci. 111, 1652-1657. https://doi.org/10.1073/pnas.1309492111.

13. Kang S, West T, Bandaru V (2013). Marginal Lands: Concept, Assessment and Management. Journal of Agricultural Science 5 (5) 2013, 129139. DOI: $10.5539 /$ jas.v5n5p129

14. Blanco-Canqui H (2010) Energy crops and their implications on soil and environment. Agron. J., 102, 403-419. http://dx.doi.org/10.2134/agronj2009.0333

15. Qin Z, Zhuang Q, Zhu X, Cai X, Zhang X (2011) Carbon consequences and agricultural implications of growing biofuel crops on marginal agricultural lands in China. Environl Sci Technol 2011:10765-72.

16. Sang T, Zhu W (2011) China's bioenergy potential. GCB Bioenergy 3, 79-90. https://doi.org/10.1111/j.1757-1707.2010.01064.x.

17. Nassi o Di Nasso N, Roncucci N, Bonari E (2013) Seasonal Dynamics of Aboveground and Belowground Biomass and Nutrient Accumulation and Remobilization in Giant Reed (Arundo donax): A Three-Year Study on Marginal Land. Bioenerg. Res.6, 725-736 (2013). https://doi.org/10.1007/s12155-012-9289-9

18. Fisher M (2010) Sustainable bioenergy: fueling biomass plants without degrading the land. CSA News.

19. Cibin R, Chaubey I, Engel B (2012) Simulated watershed scale impacts of corn stover removal for biofuel on hydrology and water quality. Hydrol. Process. 26 (11), 1629e1641. http://dx.doi.org/10.1002/hyp.8280.

20. Feng Q, Chaubey I, Her Y, Cibin R, Engel B, Volenec J, Wang X (2015) Hydrologic and water quality impacts and biomass production potential on marginal land. Environmental Modelling \& Software, Vol 72, October 2015, Pages 230-238. https://doi.org/10.1016/j.envsoft.2015.07.004

21. Philippou I (2014) Chemistry and Chemical Technology of Wood; Giahoudi-Giapouli Publications: Thessaloniki, Greece, $2014 ;$ p. 357.

22. Gao J, Barbieri C, Valdivia C (2014) A socio-demographic examination of the perceived benefits of agroforestry. Agrofor. Syst. $88,301-309$. DOI: 10.1007/s10457-014-9683-8

23. FAO (Food and Agricultural Organization) (2005) Global Forest Resources Assessment 2005. Food and Agriculture Organization Forestry Paper 147. Food and Agriculture Organization, Rome.

24. Tang Y, Xie J.-S, Geng S (2010). Marginal land-based biomass energy production in China. J. Integr. Plant Biol. 52, 112-121. DOI: 10.1111/j.1744-7909.2010.00903.x.

25. Ghezehei SB, Shifflett SD, Hazel DW, Nichols EG (2015). SRWC bioenergy productivity and economic feasibility on marginal lands. J. Environ. Manag. 160, 57-66. DOI: 10.1016/j.jenvman.2015.05.025.

26. Saha M, Eckelman MJ (2015). Geospatial assessment of potential bioenergy crop production on urban marginal land. Appl. Energy 159, 540547.

27. Gabrielle B, Bamiere L et al. (2014) Paving the way for sustainable bioenergy in Europe: technological options and research avenues for largescale biomass feedstock supply. Renew. Sustainable Energy Rev. 33, 11-25. https://doi.org/10.1016/j.rser.2014.01.050.

28. Kamperidou V, Lykidis C, Barmpoutis P (2017). Assessment of the Thermal Characteristics of Pellets Made of Agricultural Crop Residues Mixed with Wood. BioResources. 12(4) 9263-9272.

https://ojs.cnr.ncsu.edu/index.php/BioRes/article/view/BioRes_12_4_9263_Kamperidou_Thermal_Characteristics_Pellets_Crop_Residues/5673

29. Isajev V, Fady B, Semerci H, Andonovski V (2004) European Black pine - Pinus nigra: Technical guidelines for genetic conservation and use (PDF), European Forest Genetic Resources Programme.

http://www.bioversityinternational.org/fileadmin/user_upload/online_library/publications/pdfs/1035.pdf.

30. Krussman G (1985) Manual of Cultivated Conifers. Portland, Oregon U.S.A.: Timber Press. ISBN 10: 088192007X / ISBN 13: 9780881920079.

Page 8/11 
31. USDA (2016) "Robinia psudeoacacia factsheet" (PDF). Retrieved 14 July 2016. https://plants.usda.gov/factsheet/pdf/fs_rops.pdf

32. Zajac G, Szyszlak-Bargłowicz J, Goł ebiowski W, Szczepanik M (2018) Chemical Characteristics of Biomass Ashes. Energies 2018, 11, 2885; DOI:10.3390/en11112885.

33. Kumar M, Gupta RC, Sharma T (1992) Effect of carbonisation condition on the yield and chemical composition of Acacia and Eucalyptus wood chars. Biomass and Bioenergy, 3: 411-417. https://doi.org/10.1016/0961-9534(92)90037-Q.

34. Orwa C, Mutua A, Kindt R, Jamnadass R, Anthony S (2009) Robinia pseudoacacia Fabaceae - Papilionoideae L. Agroforestree Database: Tree reference and selection guide version 4.0 (http://apps.worldagroforestry.org/treedb2/AFTPDFS/Robinia_pseudoacacia.PDF)

35. Cosola G (2013) Energetic properties of european Black Pine (Pinus nigra subsp. nigra var. nigra J.F. Arnold) wood in the Trieste area. Doctoral thesis, University of Padova. http://tesi.cab.unipd.it/42711/1/Cosola_Giulio.pdf

36. Stoof CR, Richards BK, Woodbury PB et al. (2015) Untapped Potential: Opportunities and Challenges for Sustainable Bioenergy Production from Marginal Lands in the Northeast USA. Bioenerg. Res. 8, 482-501 (2015). https://doi.org/10.1007/s12155-014-9515-8

\section{Figures}
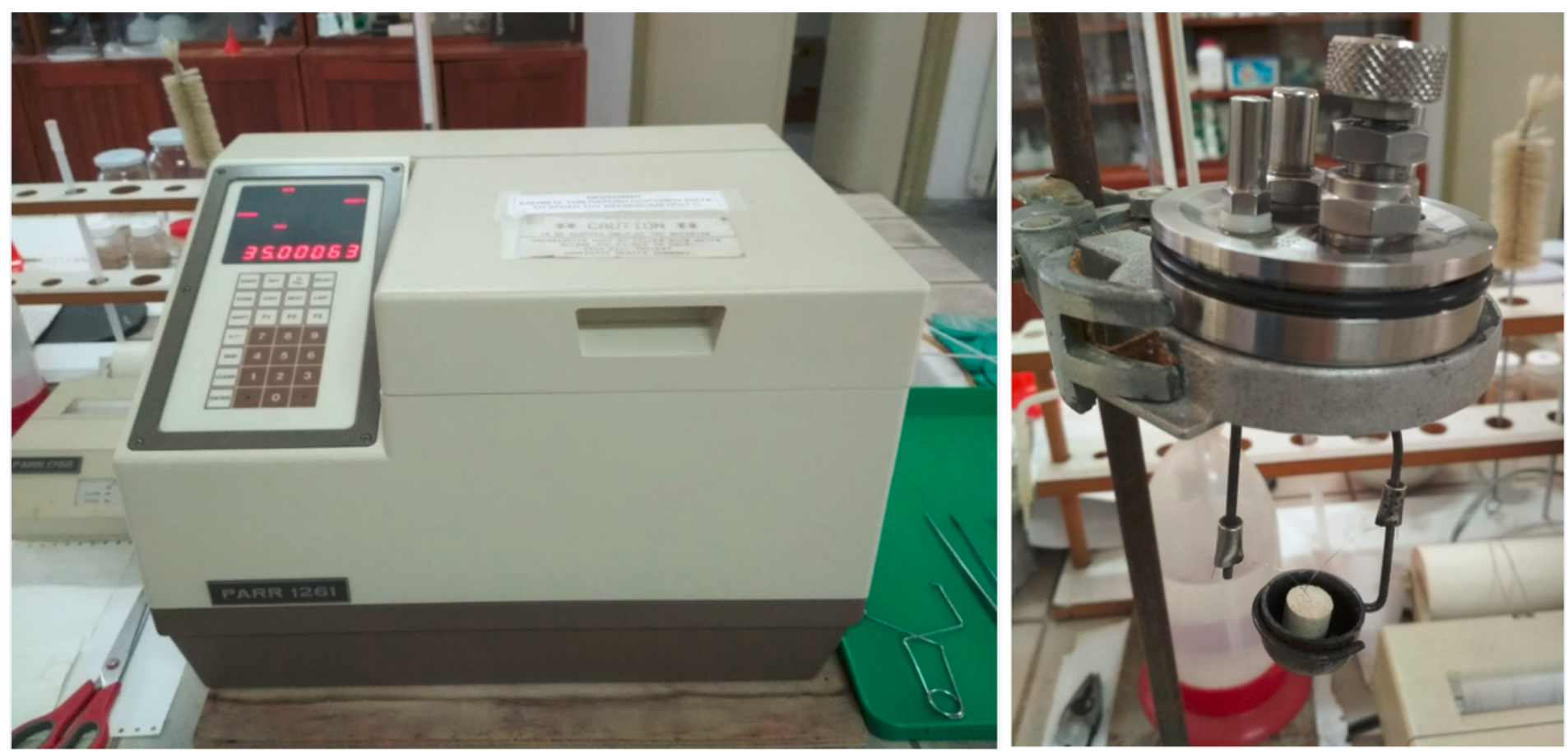

A

\section{B}

\section{Figure 1}

Isoperibol bomb calorimeter (a), sample pills prepared for the calorific value measurement process (b) 


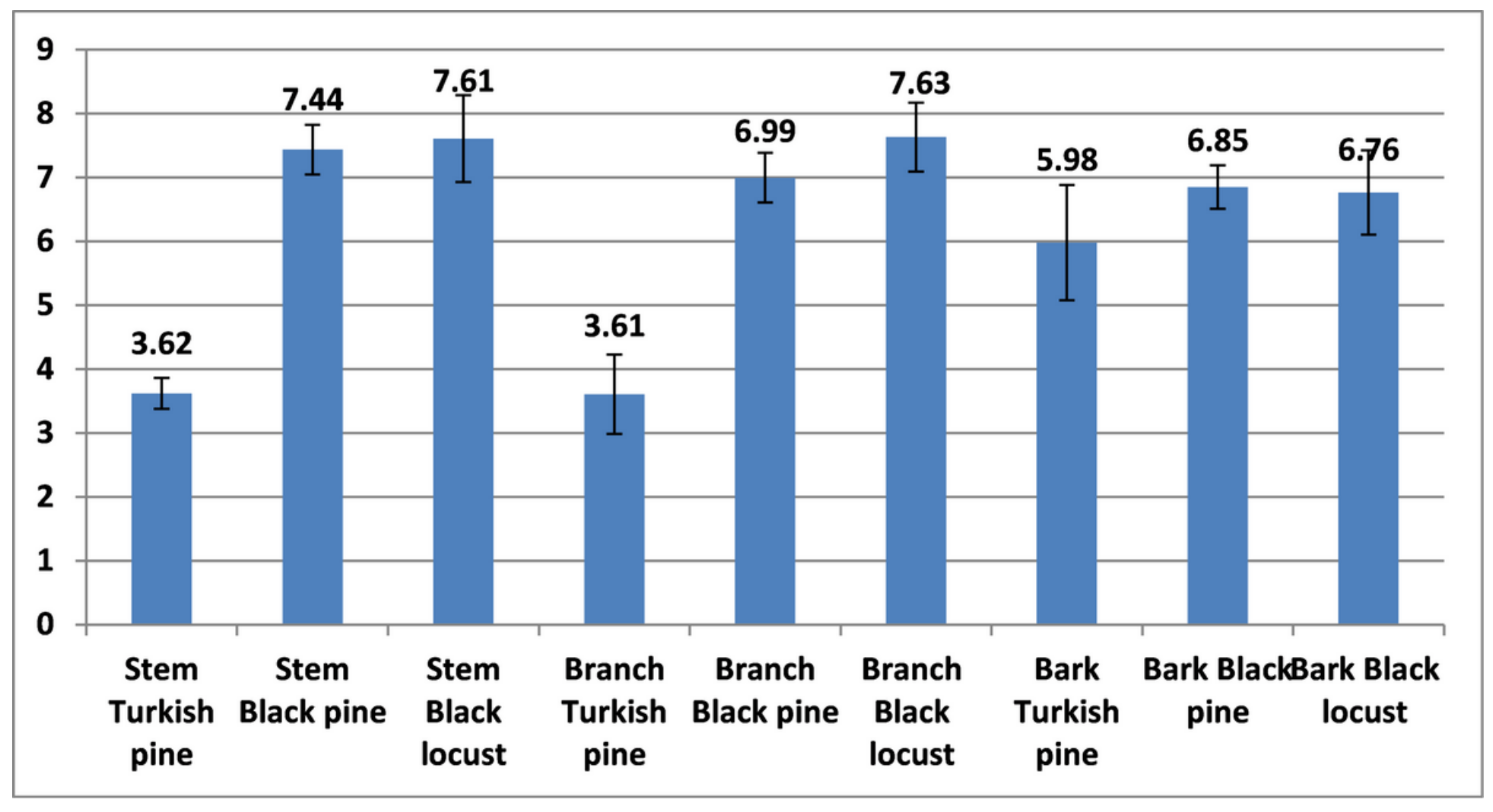

Figure 2

Equilibrium moisture content (EMC) values (\%) of the studied materials

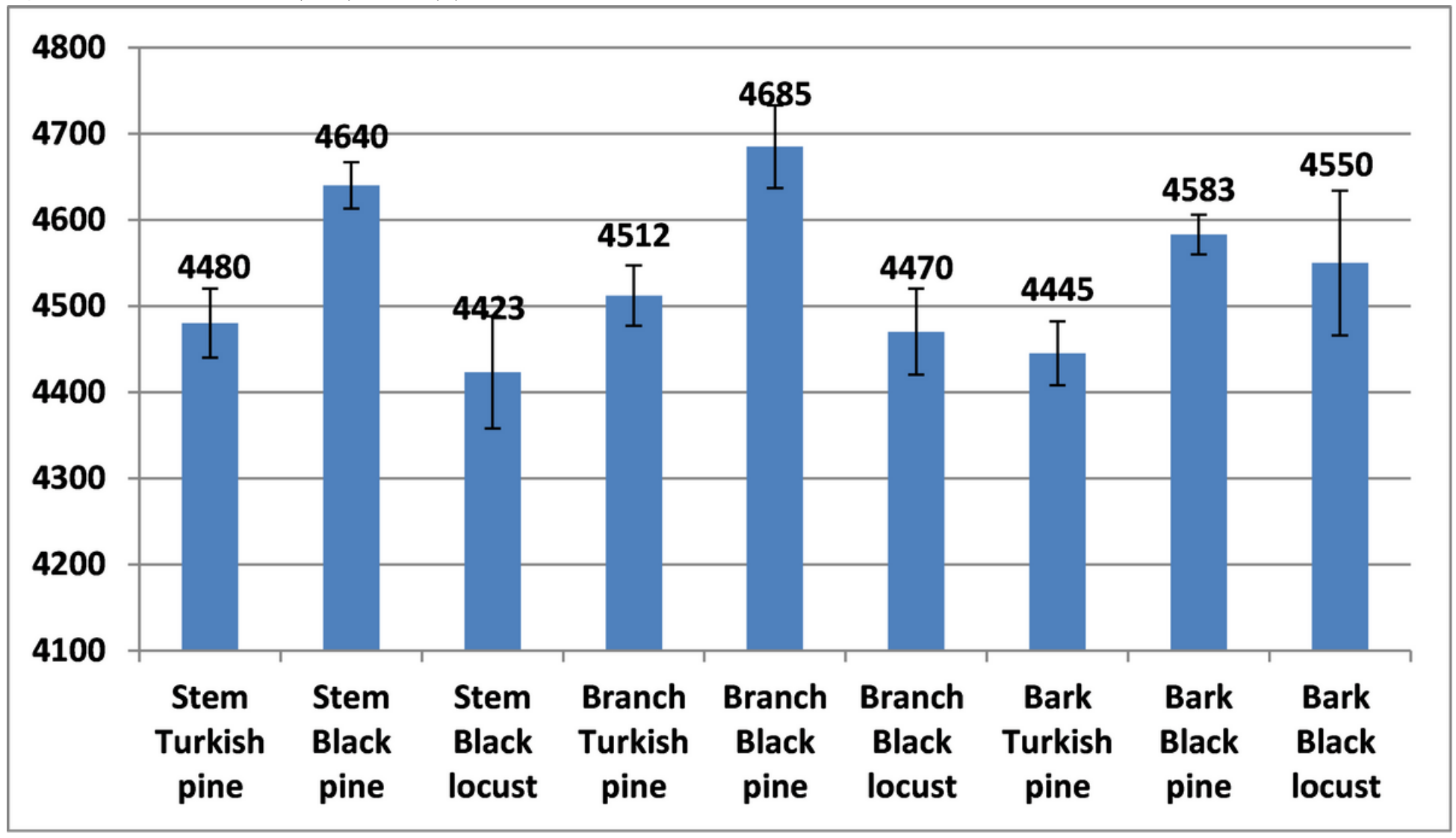

Figure 3 


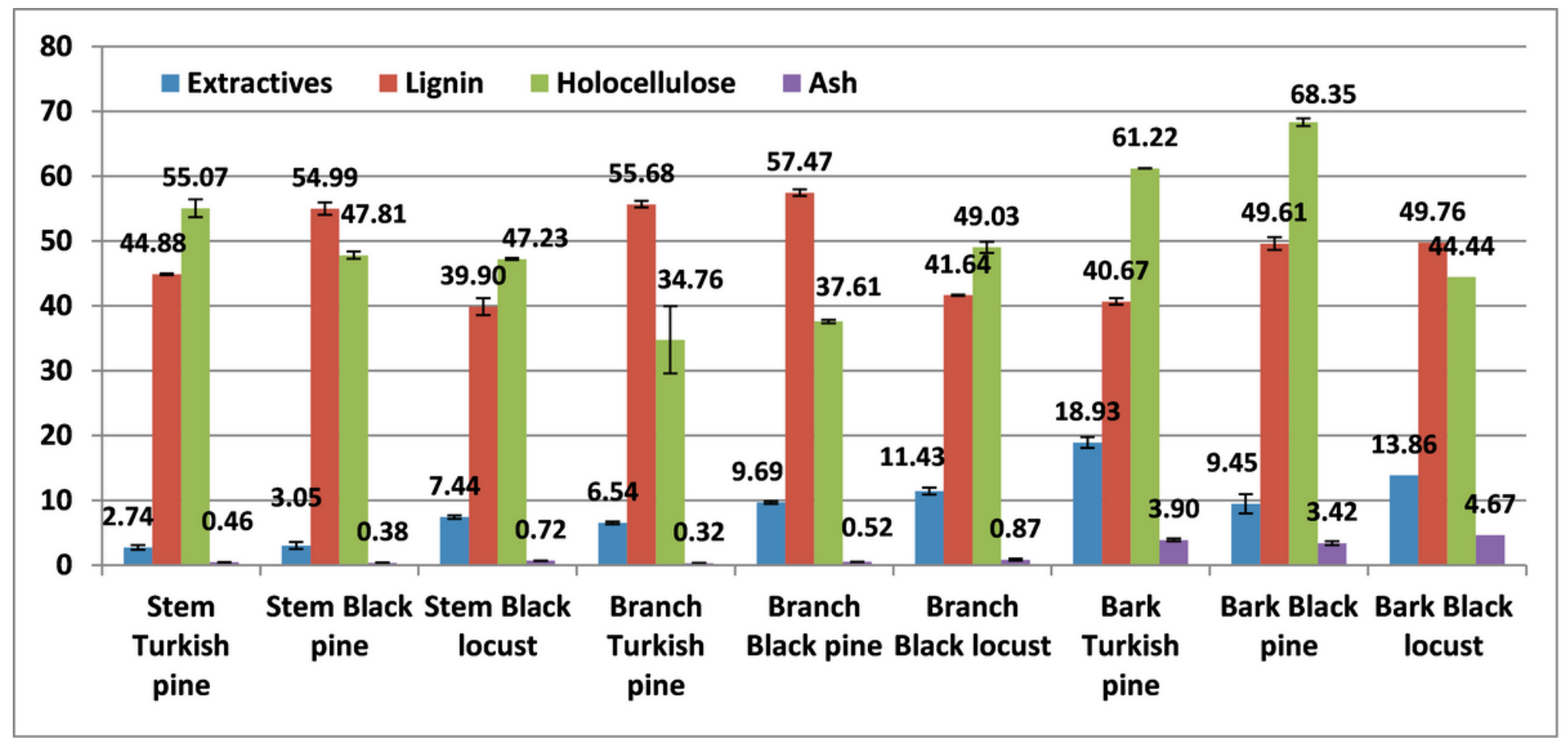

Figure 4

Net calorific value $(\mathrm{kcal} / \mathrm{kg})$ of the studied materials

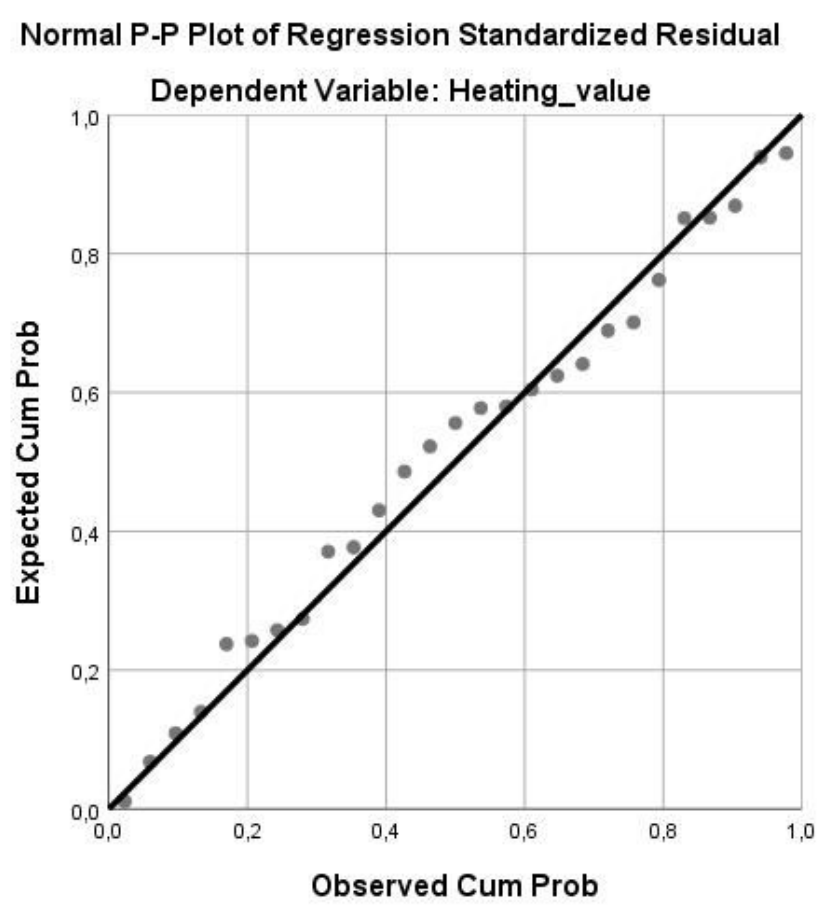

Figure 5

Normal P-P Plot of regression standardized residual of Heating value (dependent variable) and chemical components contents (independent variables) 